Portland State University

PDXScholar

1986

\title{
The grammatic closure subtest of the ITPA as a screening device
}

Cathy Newquist

Portland State University

Follow this and additional works at: https://pdxscholar.library.pdx.edu/open_access_etds

Part of the Education Commons, and the Speech and Rhetorical Studies Commons Let us know how access to this document benefits you.

\section{Recommended Citation}

Newquist, Cathy, "The grammatic closure subtest of the ITPA as a screening device" (1986). Dissertations and Theses. Paper 3708.

https://doi.org/10.15760/etd.5592

This Thesis is brought to you for free and open access. It has been accepted for inclusion in Dissertations and Theses by an authorized administrator of PDXScholar. Please contact us if we can make this document more accessible: pdxscholar@pdx.edu. 
AN ABSTRACT OF THE THESIS OF Cathy Newquist for the Master of Science in Speech and Hearing Science presented June $3,1986$.

Title: The Grammatic Closure subtest of the ITPA as a Screening Device

APPROVED BY MEMBERS OF THE THESIS COMMITTEE:

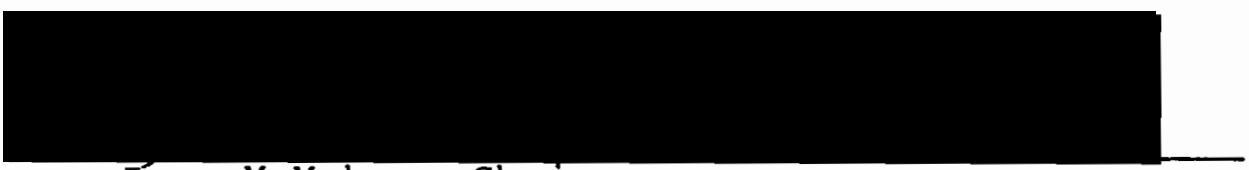
Joan McMahon, Chair

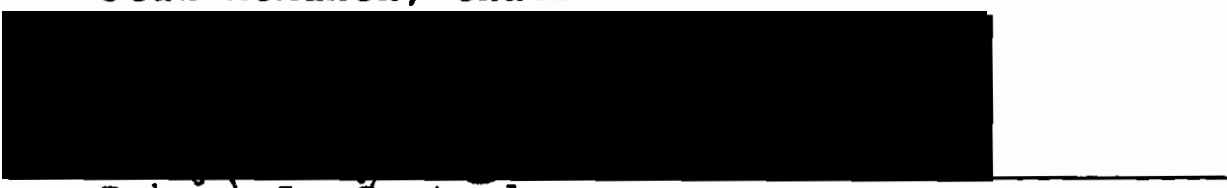

Robert L. Casteel

Identification and selection of a speech-language caseload in the school setting can be a challenging task. The initial stages of caseload selection are usually in the form of a screening procedure. Although speech-language information is gathered at that time, information about its relationship to each student's academic status is usually not obtained. Such information would be useful in a setting that requires the provision of special education services to be justified from a basis of academic need. 
The Illinois Test of Psycholinguistic Abilities'

(ITPA) Grammatic Closure subtest has been correlated to academic and intellectual measures through various studies. Its length and ease of administration make it a possible candidate for a screening device which would also provide some correlational information about academics.

The purpose of this study was to determine if the Grammatic Closure subtest of the ITPA would be a useful screening instrument in identifying first and second grade children who have co-existing speech-language and academic problems. Fifty-eight normally developing, middle class children aged 6.5 to 8.0 from an English speaking home environment participated as subjects.

The subjects responded to the items of the Grammatic Closure subtest and the California Achievement Test (CAT). The Pearson Product Moment Correlation was selected to determine the statistical correlation between the Grammatic Closure subtests' scaled scores and the CAT's grade equivalents.

A low correlation was found at the first grade level, and a moderate correlation was found at the second grade level. The results indicated that a speech-language pathologist using the Grammatic closure subtest as a screening device at the second, but not first, grade level could be reasonably assured of identifying not only those subjects with or without a language problem, but also those 
who statistically are, or are not, likely to succeed academically. However, it was suggested that the subtest be used as part of a screening procedure that would also allow the clinician to observe the subjects' spontaneous expressive speech and language. 
THE GRAMMATIC CLOSURE SUBTEST OF

\title{
THE ITPA AS A SCREENING DEVICE
}

by

CATHY NEWQUIST

A thesis submitted in partial fulfillment of the requirements for the degree of

\author{
MASTER OF SCIENCE \\ in \\ SPEECH AND HEARING SCIENCE
}

Portland State University

1986 
TO THE OFFICE OF GRADUATE STUDIES AND RESEARCH:

The members of the Committee approve the thesis of Cathy Newquist presented June 3, 1986.

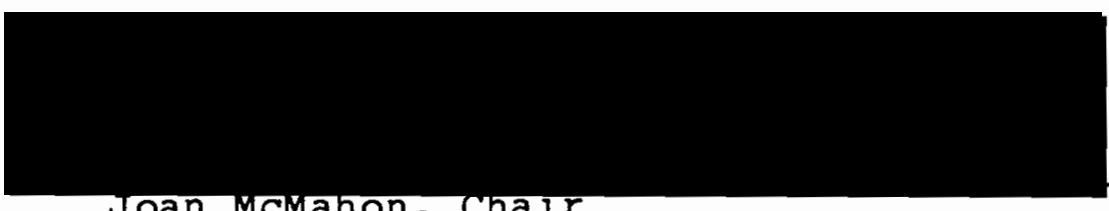

Joan Mclvahon, Chatr

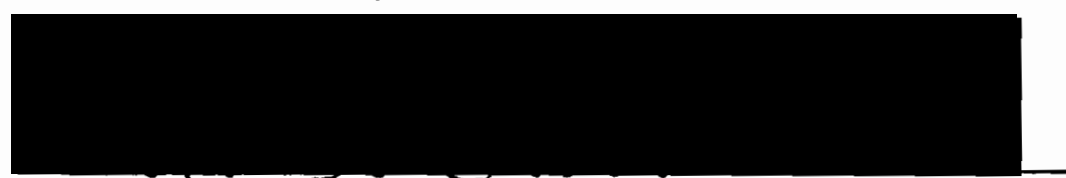

Robert L. CasteeI

APPROVED:

A

Theodore G. Grove, Head, Department of Speech Communications

Bernard Ross, Dean of Graduate studies and Research 


\section{ACKNOWLEDGEMENTS}

I am sincerely grateful for this opportunity to express my appreciation to the people who really did help to "make it all possible." My heart-felt thanks go to:

My professors and supervisors in Seattle, Portland and Bakersfield for sharing their knowledge, skill, and love of our profession.

My Brothers and Sisters in Seattle, Portland and Bakersfield for encouraging me, helping me, and believing in me.

My extended family for dispelling all in-law myths by so graciously giving of their time, money and energy.

My parents, Ron and Vivian Robinson, for giving me Iife, the love of truth, and financial help way beyond the cal1 of duty.

My husband, Dave, and our children Crystal and Emerald, for supporting me emotionally, and for laying aside their wants and needs to allow me to obtain mine.

And Jesus, for continually convincing me that apart from Him I can do nothing, but that through him I can do all things. 
TABLE OF CONTENTS

PAGE

ACKNOWLEDGEMENTS . • . . . . . . . . . . . . . . .

LIST OF TABLES • • • • • • • • • • • • • • • • . vi v vi

CHAPTER

I INTRODUCTION AND STATEMENT OF PURPOSE. . . . 1

Introduction. . . . . . . . . . . 1

Statement of Purpose. . . . . . . . 3

II REVIEW OF THE LITERATURE . . . . . . . . . . 4

Introduction. . . . . . . . . . . . 4

The Illinois Test of Psycholinguistic

Abilities (ITPA) . . . . . . . . . . 6

Criticisms of the ITPA. . . . . . . 7

Correlates of the Grammatic Closure

Subtest. . . . . . . . . . . 9

Reading

Mathematics

Spelling

Intelligence

Language

Grammatic closure as a Screening

Device . . . . . . . . . . . 15

The Need for Determining the Usefulness

of the Grammatic Closure Subtest as

a Screening Device . . . . . . . 16 
CHAPTER

PAGE

III METHODS AND PROCEDURES - . • . . . . . .

Subjects . • • • • . . • • • • • 17

Instrumentation. . . . . . . . . 17

Procedures . . . . . . . . . . . 18

Analysis of Responses. . . . . . . 19

Reliability of the Data. . . . . . 20

Analysis of the Data. . . . . . . 20

IV RESULTS AND DISCUSSION • . • • • • • • • • 21

Results. • . . . . . . . . . . 21

Discussion . . . . . . . . . . . 22

V SUMMARY AND IMPLICATIONS • . . . . . . . . 31

Summary. • . • • • . • • . • • 31

Implications . . • . . . . . . 32

Research

Clinical

BI BLIOGRAPHY • • • • • • • • • • • • • • • • • 35

APPENDIX • • • • • • • • • • . • • • • • • . 39 


\section{LIST OF TABLES}

TABLE

PAGE

I Statistical Results of Pearson Product Moment Correlations for Grammatic closure subtest Scaled Scores and California Achievement Test Grade Levels . . . . . . . . . .

II First Grade Scattergram for Grammatic Closure

Subtest Scaled Scores and California

Achievement Test Grade Levels . . . . .

II Second Grade Scattergram for Grammatic

Closure Subtest Scaled Scores and

California Achievement Test Grade Levels. . 
CHAPTER I

INTRODUCTION AND STATEMENT OF PURPOSE

Introduction

Historically, the field of speech pathology has focused on disorders of speech such as articulation, fluency, and voice. Since the 1960's, however, the scope of interest, need and knowledge has broadened to include normal language development and the remediation of disordered language concepts, reception, formulation and production (Stark, 1975; Muma, Webb and Muma, 1979). Language is the base upon which knowledge builds and without the language skills needed to order and communicate information, learning becomes inefficient (Perkins, 1971).

The speech-language pathologist in the public schools has been assuming the task of identifying students with language problems (Muma, Webb and Muma, 1979), and caseload selection is generally based upon students' performances on a device selected by the speech-language pathologist (Sommers and Hatton, 1985). Increasing emphasis in the public school systems on accountability has made it necessary for the speech-language pathologist to present rationale for taking a student into the caseload (Sommers and Hatton, 1985). Should funding, and therefore personnel, 
decrease in the future, this pressure would most likely increase.

School speech-language pathologists are hired to ameliorate speech and language problems which distract from a student's potential academic success. For example, California Education Code Section 56333 allows special education services only for students whose speech or language is disordered to the "extent that it adversely affects his or her educational performance and cannot be corrected" in the regular classroom setting.

A child with co-existing language and academic problems would, therefore, be selected over a child with a similar language status but adequate academic performance (Sommers and Hatton, 1985). A screening device which would make such a differentiation would be valuable to the speech-language pathologist involved in the school setting.

The Illinois Test of Psycholinguistic Abilities'

(ITPA) Grammatic Closure subtest has been shown to correlate with academic achievement in numerous studies as reviewed by Sedlack and Weener (1973), Kirk and Elkins (1974), Newcomer and Hammill (1975), and Kirk and Kirk (1978). The subtest takes ten minutes to administer in its entirety (Arnold and Reed, 1976), making it a possible candidate for a screening device. In addition to measuring language abilities, articulation and voice can be screened by noting the client's performance in these parameters during the 
subtest's one-to-two word responses. Fluency and spontaneous expressive language skills would need to be evaluated by an additional strategy.

\section{Statement of purpose}

The purpose of this study was to determine if the ITPA's Grammatic Closure subtest is a useful screening instrument in identifying first and second grade children aged 6.5 to 8.0 who have language deficits which coexist with academic deficits. More specifically, the scores obtained on the Grammatic Closure subtest by first and second grade children aged 6.5 to 8.0 were compared to their scores on the California Achievement Test (CAT). The essential question asked was:

Is there a significant relationship between the Grammatic closure subtest scores and academic achievement as measured by the CAT score? 
CHAPTER II

REVIEW OF THE LITERATURE

Introduction

Caseload selection for the speech-language pathologist in the public school setting can be a difficult job. The California Education Code Section 56333 states:

A pupil shall be assessed as having a language or speech disorder which makes him or her eligible for special education and related services when he or she demonstrates difficulty understanding or using spoken language to such an extent that it adversely affects his or her educational performance and cannot be corrected without special education services...

Not only must those students with speech and language problems be identified, but judgment as to how a student's speech or language problem will affect academic progress must be made. The clinician must consider which students' academic progress will suffer most if they are eliminated from the caseload, and which would benefit most from speech and language services. In the public school setting, academic outcome is the final criteria for caseload selection, and the clinician must select students who most need speech-language services in order to better achieve academically (Sommers and Hatton, 1985).

Screening instruments are used to aid the speechlanguage clinician in the initial decision making process 
(Sommers and Hatton, 1985). Generally these screening instruments center around speech and language aspects of a student's performance but do not provide information about academic status. Furthermore, such academic information usually exists in very limited degree during the initial screening periods of first grade. An approximate estimate of a student's academic achievement, or potential for it, would help the clinician decide which students may need speech-language services to better achieve academically.

The problem, then, lies in identifying an instrument that not only measures speech and language, but also provides reliable information regarding academics. Furthermore, the instrument must be within the administrating domain of the speech-language pathologist, and be sufficiently time efficient to be used as a screening device (Sommers and Hatton, 1985). Such an instrument would allow the clinician to select a caseload whose members most need speech-language services in order to achieve academically.

The Illinois Test of Psycholinguistic Abilities' (ITPA) Grammatic Closure subtest has been correlated to academic achievement in the areas of reading, mathematics and spelling as demonstrated in the reviews of numerous studies (Sedlack and Weener, 1973; Kirk and Elkins, 1974; Newcomer and Hammill, 1975; Kirk and Kirk, 1978). The 
following literature review will summarize research on academic correlation of the ITPA and its Grammatic Closure subtest.

\section{The Illinois Test of Psycholinguistic Abilities (ITPA)}

In 1964, Darley stated that "perhaps the most comprehensive test of children's language status is the Illinois Test of Psycholinguistic Abilities." Perkins (1971) affirmed that "perhaps the most comprehensive and widely used (language) test is the Illinois Test of Psycholinguistic Abilities." In 1978, however, Lumsden stated that "this test should not have been published, at least in its present form." The years separating these opposing opinions saw over fifty studies on the ITPA (Wiederholt, 1978), including criticisms by statistical researchers. But according to its authors, the ITPA was often used in violation of the original intentions and guidelines they had established for its use (Kirk and Kirk, 1978 ).

The ITPA was not intended for the purpose of classifying subjects by learning disability or intelligence, but to define intra-individual psycholinguistic differences, deficits needing remediation, and strengths to be used in the remediation process. It was designed for greatest effectiveness in meeting these purposes with children aged four to eight. For research use the test is limited to this 
age span, although for clinical use the norms were extended from ages two-and-one-half to ten for the purpose of determining deficits in the young child and strengths in the older child (Kirk and Kirk, 1978).

Kirk and Kirk (1978) contended that some studies on the ITPA were flawed by the researchers' failures to follow the research guidelines, namely the qualifications of the examiners, appropriate test administration, correct age range of the subjects, and correct interpretation of test results.

Criticisms of the ITPA

In addition to Kirk and Kirk's objections to its misuse, criticisms of the ITPA centered around analyses determining the construct validity and the internal structure of the test's battery of subtests (Carroll, 1972; Hare, Hammill and Bartel, 1973; Cronkhite and Penner, 1975). Sedlack and Weener (1973) reviewed twenty factor analysis studies on the ITPA and stated "the most striking feature of all the factor analytic work done on the ITPA is its inconsistency." Newcomer and Hammill (1976) considered the factor analytic data "so remarkably disparate that they preclude the formation of accurate conclusions..." To these points, Kirk and Kirk (1978) agreed. Sedlack and weener suggested that 
future factor-analytic work should proceed from a careful a priori theoretical framework, should use a large number of subjects from different age and ability subpopulations and should be done by those with a thorough grasp of factor-analytic procedures.

Each subtest of the ITPA was also subjected to factor analyses. Of interest in this study are the conclusions related to the Grammatic Closure subtest. originally purported to tap skills at the automatic level, the Grammatic Closure subtest factored out at the representational level (Cohen, 1973). Responses at the "automatic level" are habitual and highly organized and integrated. Responses at the "representational level" require a "complex mediating process of utilizing symbols which carry... meaning..." (Kirk and Kirk, 1978). As proposed by Kirk and Kirk, construct validity of the Grammatic closure subtest was not supported.

Neither is the internal structure of the Grammatic Closure subtest useful in differential diagnosis. Cronkhite and Penner (1975) found that the ITPA's composite score (PLA) could be predicted from the Grammatic closure subtest with a correlation of 0.934 making it an indicator of overall ability rather than of specific skill. Cronkhite and Penner (1975) characterized the Grammatic closure subtest as a test of "representational-organizing". They stated that

skills necessary to serve this function involve use of language as an organizing device. Possession of such skilis is indicated by an extensive receptive vocabulary and understanding of the complex rules of phonemics, morphemics, and syntax. 
Thus, the Grammatic closure subtest requires competent use of several divergent, crucial language abilities. This tapping of abilities may explain the subtest's high correlation $(0.934)$ to the overall score of the ITPA (Cronkhite and Penner, 1975).

Correlates of the Grammatic Closure Subtest

Performance on the ITPA's Grammatic Closure subtest has been repeatedly correlated to academic achievement. Sedlack and Weener (1973) reviewed twenty studies, Kirk and Elkins (1974) reviewed fourteen studies, Newcomer and Hammill (1975) reviewed twenty-eight studies and Kirk and Kirk (1978) reviewed nine studies in which the ITPA was viewed in relationship to various intellectual and academic measures including the California Achievement Test, the Stanford Achievement Test, the Wide Range Achievement Test, the Metropolitan Achievement Test, the Weschler Intelligence Scales for Children, and the Stanford-Binet Intelligence Scale. The Grammatic Closure subtest has been correlated to academic achievement in the areas of reading, mathematics and spelling.

Reading

Reading is a language-based skill (Stark, 1975) necessary for academic achievement (Perkins, 1971). In the school setting, when a student with reading problems is 
referred to a child study team, the speech-language pathologist is often called upon as a team member to screen the student for language problems which may be contributing to the reading problem (Neuman, 1979). Although the speech-language pathologist should be able to determine if speech-language services are pertinent to a particular student's reading problem, this information is not usually gathered at the screening level.

In the studies reviewed by Kirk and Kirk (1978), eleven of the ITPA subtests inconsistently correlated to reading depending on the age (six to ten years) or grade (first through fourth) of the subjects, and upon the method of reading instruction used during the ten year period (1962-1972) investigated. But the Grammatic Closure subtest remained a correlate of reading performance regardless of these variables.

Investigating the variable results of studies on the ITPA subtests, Newcomer and Hammill (1975) approached the problem by treating the joint results of twenty-eight studies as one giant study. They looked at studies conducted between 1965 and 1975, with 4,253 total subjects ranging in age from five to ten (EMR ages ranged from eight to fourteen), and variously classified as "normal," "LD," "disadvantaged," "EMR," "failing," "high risk," "conduct problems," "reading problems," and "males." A total of 820 correlational coefficients between the ITPA subtests and 
reading were analyzed. Grammatic Closure ( $r=.42)$ was among three subtests to significantly correlate to reading, along with the ITPA composite score. Newcomer and Hammill (1975) stated that when the influence of intelligence upon the relationship is disregarded "Grammatic Closure evidenced both predictive and diagnostic value for all academic abilities."

When Newcomer and Hammill (1975) examined five studies which were controlled for intelligence. Grammatic closure alone remained significant $(r=.38)$. Newcomer and Hammill stated

If one maintains that only the results from which the influence of mental ability have been extracted can be considered with confidence, then Grammatic Closure alone among the subtests would have demonstrated validity. Both predictive and diagnostic validity of this subtest for reading is strongly indicated and there is some evidence that it has diagnostic validity for arithmetic as well.

When longitudinal studies were considered, Grammatic Closure was not a significant reading predictor, being replaced by the Auditory Association subtest (Newcomer and Hammill, 1975). This would indicate that information obtained from Grammatic Closure would only be useful in signaling a present linguistic problem which may be interfering with reading ability and therefore in need of further investigation. This, of course, is the purpose of a screening device (Sommers and Hatton, 1985). 


\section{Mathematics}

The Newcomer and Hammill (1975) study previously described analyzed 154 coefficients between the ITPA subtests and mathematics. Similar to the results found for reading, only Grammatic Closure $(r=.40)$, Auditory Association $(r=.40)$ and the Composite Score $(r=.51)$ were significantly predictive (at or above a .35 correlational coefficient in that study). However, when the influence of intelligence was eliminated, no significant correlations were found.

\section{Spelling}

Hammill and Newcomer (1975) also investigated 178 coefficients between the ITPA subtests and spelling. In this case, only Grammatic Closure $(r=.41)$ was a significant correlation. Again, when the influence of intelligence was eliminated, no significant correlations were found.

\section{Intelligence}

Intelligence, or IQ, scores generate useful information in evaluating academic progress. The IQ score, whether high or low, when compared to academic progress, can help to indicate whether a student is performing below, near, or above expected academic potential. In the case of poor or under-achievers, the speech-language pathologist must be able to determine if the problem is language based and if speech-language services would benefit the student 
in question. Again, information about IQ is not generally obtained from a routine speech-language screening.

Several researchers have found the ITPA to be useful in evaluating mentally retarded students (Bateman and Wetheral, 1965; Mueller, 1969). Hiroshen found that "the Total Language Score of the ITPA, at least at the kindergarten level, is as valid a predictor as is the stanfordBinet IQ for school achievement two years later." Huizinga (1971) found that the ITPA correlated 0.90 with the Stanford-Binet Intelligence Scale, and 0.80 with the Weschler Intelligence Scales for Children (WISC). Humphrey and Rice (1973) found a 0.94 correlation between the WISC between the expressive portion of the Northwestern Syntax Screening Test (NSST) and the Grammatic Closure subtest, confirming its value as a screening measure of language skills. Reese (1976) found a modest correlation $(p<0.05)$ between the standard Grammatic closure subtest performance and an experimental version in which the subjects restated each Grammatic closure subtest item in their own words. When Larson and Summers (1982) correlated matched grammatical items from the Grammatic closure subtest and the Berry-Talbot Exploratory Test of Grammar, they found a moderate correlation $(r=0.48)$ with a higher frequency of correct responses on the Grammatic Closure subtest than on the Berry-Talbot Exploratory Test of Grammar. Luick, Agranowitz, Kirk, and Busby (1982) found that ninety-seven 
skills which are not specific to language learning." These studies indicate that the Grammatic closure subtest would yield an approximate idea of intelligence during screening, allowing the speech-language pathologist to make referrals for further evaluation if deemed necessary.

\section{Language}

The Grammatic closure subtest has also been correlated to several language measures. As stated previously, Cronkhite and Penner (1975) correlated (0.934) the Grammatic closure subtest to the ITPA's composite score. Newman (1972) found a 0.65 correlation ( 428 of the variance) between the expressive portion of the Northwestern Syntax Screening Test (NSST) and the Grammatic closure subtest, confirming its value as a screening measure of language skills. Reese (1976) found a modest correlation $(p<0.05)$ between the standard Grammatic Closure subtest performance and an experimental version in which the subjects restated each Grammatic Closure subtest item in their own words. When Larson and Summers (1982) correlated matched grammatical items from the Grammatic closure subtest and the Berry-Talbot Exploratory Test of Grammar, they found a moderate correlation $(r=0.48)$ with a higher frequency of correct responses on the Grammatic Closure subtest than on the Berry-Talbot Exploratory Test of Grammar. Luick, Agranowitz, Kirk, and Busby (1982) found that ninety-seven 
percent of 237 children assigned to classes for severe oral language handicaps exhibited their lowest ITPA scores in the Auditory Association and Grammatic Closure subtests.

Grammatic Closure as a Screening Device

As discussed above, the ITPA's Grammatic Closure subtest has been shown to correlate to present levels of test performance in reading, mathematics, spelling, intelligence, and language skills. Grammatic closure's potential as a screening device is strengthened by its ease of administration. Taking only ten minutes to administer in its entirety (Arnold and Reed, 1976), it requires one-to-two word responses which are determined to be correct $(+)$ or incorrect $(-)$ by the examiner according to the manual instructions. Scoring is quick and simple (Kirk, McCarthy and Kirk, 1968).

The age range of four to eight years covers a crucial foundational learning period of kindergarten, first, second and third grades (Wiig and semel, 1970). The norms also extend downward to age two-and-one-half, and upwards to age ten which would increase clinical, if not research, usefulness to include pre-school and older elementary children at the discretion of the clinician.

Sedlack and weener (1973) noted that middle class white children perform better on the Grammatic closure subtest than lower class non-white children. However, 
Dunchan and Baskervill (1977) found a predictable pattern of responses from Black English speaking children to the Grammatic Closure subtest items. They, along with Arnold and Reed (1976), suggested that the subtest could be adapted for use with Black English speakers if the examiner was trained to recognize appropriate and correct responses for that dialect.

The Need for Determining the Usefulness of the Grammatic Closure subtest as

a Screening Device

As discussed above, speech-language pathologists in the public school setting must identify students with a speech or language problem which may have negative influence on the student's academic performance. A screening device which would help make such a discrimination would be valuable to the clinician.

Although many studies have been done correlating the ITPA subtests to tests of academic achievement, they often used subjects which were at the upper limits of, or actually exceeded, the research guideline's age limitations. None reviewed by this examiner were administered for the purpose of speech-language screening. The current study was designed to determine the correlation of first and second grade children's scores on the California Achievement Test (CAT) and the Grammatic Closure subtest of the ITPA used according to its test manual's instructions. 
CHAPTER III

\section{METHODS AND PROCEDURES}

subjects

Fifty-eight normally developing children aged 6.5 to 8.0 were selected as subjects. Since Berko (1958) found no sex differences in performance on morphological tasks, the children were chosen without preference to sex from Temple Christian School, a private grade school in a predominately middle class area of Portland, Oregon.

Parents of all children in first and second grade were sent permission forms (see Appendix A) which explained the study and its purpose. Children who returned signed permission forms were screened for inclusion in the study. Criteria for inclusion were: l) a native English speaking home environment as reported by school personnel and files, and that 2) audiometric screening was passed at $25 \mathrm{~dB}$ at $500,1000,2000$, and $4000 \mathrm{~Hz}$ in the better ear.

\section{Instrumentation}

A portable Beltone 10D audiometer, ANSI 1969, was used to conduct the audiometric screening. 
The Grammatic Closure subtest of the ITPA (Kirk, McCarthy and Kirk, 1968) was used to evaluate the subjects' ability to complete sentences using correct morphemic forms. The morphemes to be produced by the subject included grammatical forms (plurals, verb tenses, possessives), space, time and descriptor forms (prepositions, adjectives, adverbs) and certain idiomatic word usages for a total of thirty-three responses (see Appendix B).

A Panasonic tape recorder with condensor microphone, Model RQ309DS was used to record the subjects' responses to the Grammatic Closure subtest items.

The California Achievement Test (CAT) (Tiegs and Clark, 1970), a nationally used scholastic achievement measurement, was used to assess academic status.

\section{Procedures}

A permission form letter explaining the purpose and nature of the study was sent to parents of children enrolled in first or second grade at Temple Christian School. Hearing screening was administered to those subjects who had returned permission forms. Each child was individually screened in a quiet room at the school library. Children meeting criteria were included in the study.

The recording instrument had been previously set up in the above mentioned room with padding under the recorder to minimize ambient noise. The examiner sat across from the 
subject at a table, and administered the Grammatic closure subtest according to test manual instructions. Each subject responded to the thirty-three items of the Grammatic closure subtest. Responses were immediately recorded on the test form, and the tape recorded responses were later used to verify the accuracy of the examiner's evaluation of the subjects' responses.

The CAT was administered according to test manual instructions by the first and second grade classroom teachers, each with over five years of experience in administrating the CAT. The test was administered in the child's regular classroom setting one month following the completion of the Grammatic Closure administration.

\section{Analys is of Responses}

All responses were analyzed by the examiner according to ITPA test manual instructions. The Grammatic closure subtest requires all test items to be scored correct $(+)$ or incorrect $(-)$. Correct responses are totaled to obtain a raw score which is converted into an age-adjusted scaled score by using the tables provided in the test manual.

The CAT was scored by school personnel according to the test manual instructions, and grade equivalent scores of students involved in this study were provided to the examiner by the school office. 
Reliability of Data

Responses to the Grammatic Closure subtest were tape recorded during the testing sessions. Inter-judge reliability $(.90)$ was determined between this examiner and an ASHA certified speech pathologist with five years of experience in administering the Grammatic Closure subtest. Three taped samples of the Grammatic Closure subtest were randomly chosen by a third party from the fifty-eight available recordings, and presented independently to the judges for scoring. Intra-judge reliability (.97) was determined only for this examiner. This was accomplished when the scores obtained during the original testing were compared to those obtained by this examiner during the inter-judge procedure.

\section{Analysis of the Data}

This study yielded two sets of data from fifty-eight subjects: 1) the scaled scores from the Grammatic closure subtest, and 2) the grade equivalent scores from the CAT (see Appendix $C$ ). In comparing the sets of data from the Grammatic Closure subtest and the CAT, the Pearson Product Moment Correlation was determined to be the appropriate statistical analysis for the data based on statistical tests run to determine skewness and kurtosis. All statistical analyses were run on computer by Dr. John Dirkse, head of mathematics at California State College Bakersfield. 
CHAPTER IV

\section{RESULTS AND DISCUSSION}

\section{Results}

In this study the Illinois Test of Psycholinguistic Abilities' (ITPA) Grammatic Closure subtest scores were compared to the California Achievement Test (CAT) scores for fifty-eight first and second grade children aged 6.5 to 8.0 . The research question asked was: Is there a significant relationship between the Grammatic Closure subtest scores and academic achievement as measured by the CAT score?

The Grammatic Closure raw scores were converted to age adjusted scaled scores by using the tables provided in the test manual. The CAT scores were converted into overall grade level equivalents using that test's procedures. These two sets of data are displayed in Table $I$.

TABLE I

STATISTICAL RESULTS OF PEARSON PRODUCT MOMENT CORRELATIONS FOR GRAMMATIC CLOSURE SUBTEST SCALED SCORES AND CALIFORNIA ACHIEVEMENT TEST GRADE LEVELS

\begin{tabular}{lcccc}
\hline Group & N & r & $\mathrm{r}^{2}$ & $\mathrm{P}$ \\
\hline All subjects & 58 & .2077 & .04315 & .059 \\
First grade & 36 & .2419 & .05833 & .078 \\
Second grade & 22 & .5267 & .27735 & .006 \\
\hline
\end{tabular}


The first and second grade combined data yielded a low correlation of $r=.21$ with Grammatic Closure accounting for four percent of the variance $\left(r^{2}=.04315\right)$. This finding is not significant because of the low level of confidence $(P=.059)$.

When considered alone, the first grade data yielded a low correlation of $r=.24$ with Grammatic closure accounting for six percent of the variance $\left(r^{2}=.05833\right)$. This finding is not significant because of the low level of confidence $(P=.078)$.

When the second grade data was considered alone, the scores yielded a moderate correlation of $r=.53$ with Grammatic Closure accounting for twenty-eight percent of the variance $\left(r^{2}=.27735\right)$. This finding is significant because of the high level of confidence $(P=.006)$.

To summarize, Grammatic Closure yielded a low correlation with the first grade CAT scores, and a moderate correlation with the second grade CAT scores.

\section{Discussion}

In the search of the literature by this examiner, studies about the ITPA and its subtests in comparison to various academic and intellectual measures were reviewed. This study differs from the studies reviewed in that it sought to investigate the usefulness of the Grammatic Closure subtest in a school setting's speech-language 
screening procedure at the lower (first and second grade) levels. Would the Grammatic Closure subtest be significantly useful in identifying this age level of students with co-existing academic and speech-language problems? The results of the study indicated a low correlation at the first grade level, and a moderate correlation at the second grade level in this population. This would indicate that the speech-language pathologist using the subtest in a screening procedure at the second, but not first, grade level could be reasonably assured of accurately identifying not only those students with or without a speech-language problem, but also those who statistically are, or are not, likely to succeed academically. In the school setting, this screening information would be useful to the speech-language pathologist who is part of the larger educational team. In any screening, the goal is to reduce false positive and false negative identifications as much as possible (Sommers and Hatton, 1985). When the goal of the speech-language screening is to identify those subjects with academic problems due to speech-language problems, the subjects described below fell into the false positive (subjects $A, B$, and $C$ ) and false negative (subjects $T$ through Z) categories.

In examining the scattergram for the thirty-six first graders (see Table II), thirty-three of the subjects fell 
into the expected correlational pattern, and three of the subjects did not. Subjects $A, B$, and $C$ earned borderline Grammatic Closure scores of 29 or below, but scored at grade level $+/-$ three months on the CAT. This false positive group of subjects had relatively low Grammatic Closure scores and high CAT scores. The low language skills measured by the Grammatic Closure subtest were not reflected in the academic performance on the CAT. These subjects probably would be evaluated to establish the degree of language problem, and, depending upon the evaluation results, included in the speech-language caseload or placed on a recheck list to follow interplay of language and academic skills.

In examining the scattergrams for the twenty-two second graders (see Table III), fifteen of the subjects fell into the expected correlational pattern, and seven of the subjects did not. Subjects $\mathrm{T}$ through $\mathrm{Z}$ earned average scores ranging from 31 to 41 on the Grammatic closure subtest, but scored 6 to 12 months below grade level on the CAT. This false negative group of subjects had relatively high Grammatic Closure scores and low $\underline{C A T}$ scores. The low academic performance as measured by the $\underline{C A T}$ was not reflected in the language skills measured by the Grammatic Closure subtest, suggesting that these subjects' poor academic performance may be due to non-language related learning problems (such as visual 
FIRST GRADE SCATTERGRAM FOR GRAMMATIC CLOSURE SUBTEST SCALED SCORES AND CALIFORNIA ACHIEVEMENT TEST GRADE LEVELS

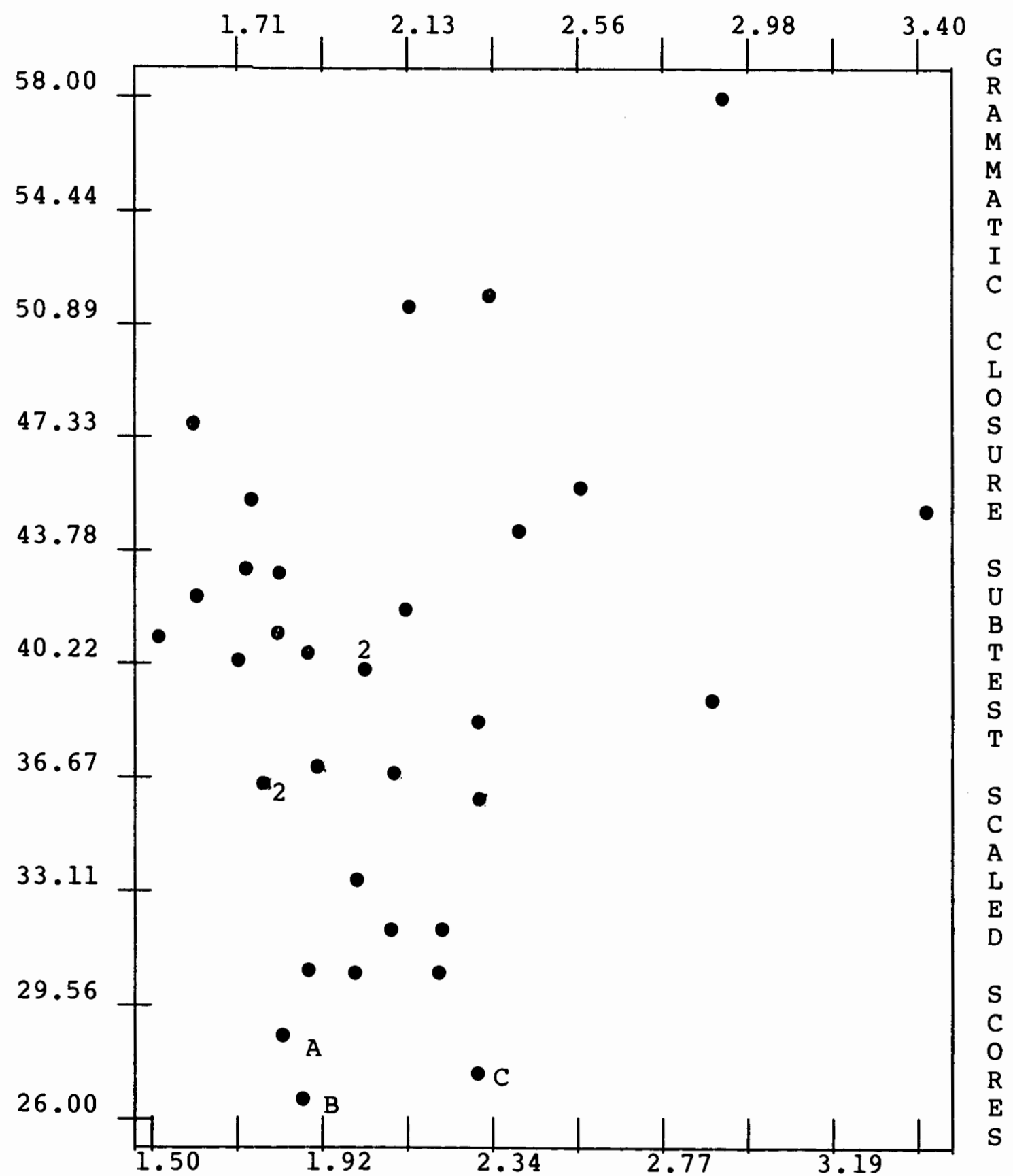

CALIFORNIA ACHIEVEMENT TEST GRADE LEVELS 
SECOND GRADE SCATTERGRAM FOR GRAMMATIC CLOSURE SUBTEST SCALED SCORES AND CALIFORNIA ACHIEVEMENT TEST GRADE LEVELS

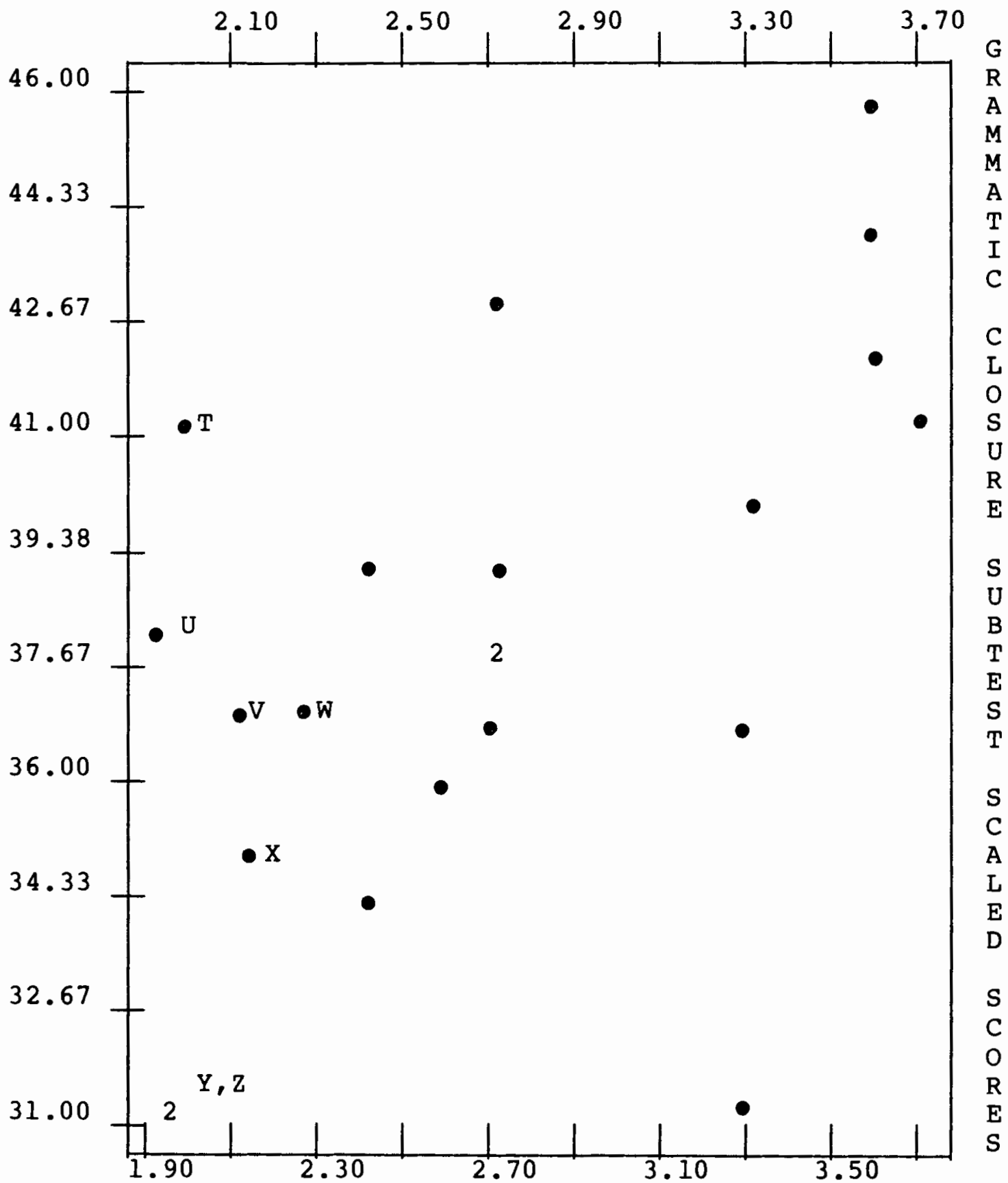


perception, social-emotional adjustment, etc.). Therefore, these subjects would not be initially presented to a child study team by the speech-language pathologist. However, the screening information gathered by the speech-language pathologist could be used to encourage the team members to explore all other screening avenues before referral and actual testing for special education services were initiated.

In this study all false positive subjects were first graders. Perhaps the maturational effects of language development played a part in that phenomenon. The low Grammatic Closure scaled scores could have been due to numerous slowly developing, but not abnormally developing, morphological forms at the first grade level. Or perhaps the demands of language at the first grade level were not yet sufficient to affect the overall academic performance. No first grader in the study was more than four months below grade level academically.

In contrast to the total false positive population being first graders, all false negative subjects were second graders. Again, the maturational effects of language could have played a part. The second grade population was reaching the upper limits of the Grammatic closure subtest's research usefulness. All but two of the twenty-two subjects' scaled scores were above the low average range. As suggested earlier, the low academic performances of 
subjects $T$ through $Z$ appear to be from non-language problems. Or perhaps the language demands upon the second grade subjects were not those tapped by the Grammatic closure subtest.

However, Cronkhite and Penner (1975) inferred that appropriate performance on the Grammatic Closure subtest would indicate the ability to use language as an "organizing device.... indicated by an extensive receptive vocabulary and understanding of the complex rules of phonemics, morphemics, and syntax". In addition, to succeed on the subtest, the subjects must visually analyze and gain meaning from the picture stimuli, auditorilly receive and process the examiner's statements, perceive that a completion is needed and that his task is to produce it, retrieve a logical and linguistically correct response, and produce that response in intelligible speech. Thus, the Grammatic Closure subtest requires competent use of several divergent, crucial language abilities. This tapping of abilities may explain the subtest's high correlation $(0.934)$ to the overall score of the ITPA (Cronkhite and Penner, 1975), and would tend to negate the opinion that the Grammatic Closure was not tapping the language skills needed to succeed academically at the second grade level.

Impressions of this examiner during the administration of the Grammatic Closure subtest was that it provided concise and valuable information about the subjects' 
abilities to process 1 inguistic information and respond appropriately. Of the fifty-eight subjects, those with articulation and voice problems were also easily identified during the one-to-two word responses.

Likewise, those with developmental morphological errors were easily identified. As in the Dunchan and Baskervill (1977) study, the majority of errors were limited to those described in the ITPA test manual, and followed an orderly pattern of appearance and disappearance based upon age (see Appendix D). Of significance to this study, however, were the erratic responses of some subjects, which were warning signals to this examiner during the screening process. Subjects who scored in the lower tenth percentile of the subjects tested seemed to have difficulty grasping that a completion was required, or finding any response (correct or incorrect) with which to complete it, especially at the beginning of the test procedure. When these subjects finally understood that a response was required, the answers were most often incorrect, and sometimes seemingly bizarre. This lower ten percent of subjects (subjects A, B, C) was quite set apart from the rest of the population examined with scaled scores in the twenties. In this study's population, the Grammatic Closure subtest was very useful clinically in identifying students who needed further evaluation. 
The one most obvious Iimitation of the Grammatic closure subtest as a screening device is the one-to-two word response format which provides no opportunity to observe the subjects' spontaneous expressive speech and language. If the subtest were used in a screening procedure, a supplementary technique would be required to elicit connected speech. The clinician could use that time to evaluate fluency, pragmatics and spontaneous expressive speech and language skills. 
CHAPTER $V$

SUMMARY AND IMPLICATIONS

Summary

Identification and selection of a speech-language caseload in the school setting can be a challenging task. The initial stages of caseload selection are usually in the form of a screening procedure. Although speech-language information is gathered at that time, information about its relationship to each student's academic status is usually not obtained. Such information would be useful in a setting that requires the provision of special education services to be justified from a basis of academic need.

The Illinois Test of Psycholinguistic Abilities' (ITPA) Grammatic Closure subtest has been correlated to academic and intellectual measures though various studies. Its length and ease of administration make it a possible candidate for a screening device which would also provide some correlational information about academics.

The purpose of this study was to determine if the Grammatic Closure subtest of the ITPA would be a useful screening instrument in identifying first and second grade children who have co-existing speech-language and academic 
problems. Fifty-eight normally developing, middle class children aged 6.5 to 8.0 from an English speaking home environment participated as subjects.

The subjects responded to the items of the Grammatic Closure subtest and the California Achievement Test (CAT). The Pearson Product Moment Correlation was selected to determine the statistical correlation between the Grammatic Closure subtests' scaled scores and the CAT's grade equivalents.

A low correlation was found at the first grade level, and a moderate correlation was found at the second grade level. The results indicated that a speech-language pathologist using the Grammatic Closure subtest as a screening device at the second, but not first, grade level could be reasonably assured of identifying not only those subjects with or without a language problem, but also those who statistically are, or are not, likely to succeed academically. However, it was suggested that the subtest be used as part of a screening procedure that would also allow the clinician to observe the subjects' spontaneous expressive speech and language.

\section{Implications}

\section{Research}

Considering the correlations found in this study, a speech-language pathologist could use the Grammatic 
Closure subtest to identify second, but not first, grade students who have co-existing language and academic problems. Several areas of further research emerge as a result of the study.

First, what is the longitudinal relationship of second grade Grammatic Closure scores to, for example, fourth grade academic achievement scores? At the fourth grade level basic skills receive minimal attention in the regular classroom and underlying linguistic deficits tend to be magnified (Wiig and semel, 1970).

Secondly, if the CAT's reading, mathematics and spelling scores are separated, what would the correlations be at the second grade level? Does the Grammatic Closure subtest correlate more with specific academic skills at this lower grade level as it did in other studies using older students?

Thirdly, can speech-language aids or volunteers be trained to use the Grammatic closure subtest in the screening procedure? How extensive would the training need to be? What level of inter-judge agreement would exist between their evaluations and that of experienced speech-language pathologists?

Finally, could a significant correlation between Grammatic closure and academic skills exist at the kindergarten and pre-school levels? The Grammatic closure subtest's limit of research usefulness goes down to age 
four. Early identification of language problems which correlate with academic problems would be advantageous to the clinician as well as the student.

Answers to these questions would help to provide a framework to evaluate the larger scope of the Grammatic closure subtest's usefulness in the academic setting.

\section{Clinical}

When used with another technique to screen spontaneous expressive speech and language, the Grammatic Closure subtest appears to be a useful screening device to identify second, but not first, grade students with co-existing language and academic problems. Whether used as a beginning-of-the-year procedure, or upon child study team or teacher requests for screening, the speech-language pathologist has a statistically useful score from which to work. In addition, false positive and false negative errors can be avoided by recording the subjects' responses in order to make a clinically sound judgement in regard to the need for further evaluation. 


\section{BIBLIOGRAPHY}

ARNOLD, K., \& REED, L. (1976). The grammatical closure subtest of the ITPA: a comparative study of black and white children. Journal of Speech and Hearing Disorders, $41,477-485$.

BATEMAN, B., \& WETHERAL, J. (1965). The role of the ITPA in differential diagnosis and program planning for mentally retarded. American Journal of Orthopsychiatry, $35,465-472$.

BERKO, J. (1958). The child's learning of English morphology. Word, 14, 150-177.

California Department of Education, Education Code, Title V Regulations, Section 56333.

CARROLL, J. (1972). Critique of the Illinois Test of Psycholinguistic Abilities. In O.K. BUROS (ED)

Seventh Mental Measurement Yearbook (pp. 819-823). Highland Park, N.J.: Gryphon.

COHEN, A. (1973). Smallest space analysis of the Revised Illinois Test of Psycholinguistic Abilities. Psychology in Schools, 10, 107-110.

CRONKHITE, G., \& PENNER, K. (1975). A reconceptualization and revised scoring procedure for the ITPA based on multivariant analysis of the original normative data. Journal of Speech and Hearing Research, 18, $506-520$.

DARLEY, F. (1964). Diagnosis and Appraisal of Communication Disorders (pp. 15-25), New Jersey: Prentice Hall.

DUNCHAN, J., \& BASKERVILL, R. (1977). Responses of black and white children to the grammatic closure subtest of the ITPA. Language, Speech and Hearing Services in Schools, $8,126-132$.

GUILFORD, J. (1956). Fundamental Statistics in Psychology and Education (pp. 135-151, 370). New York: McGraw Hill. 
HAMMILL, D. , PARKER, R. \& NEWCOMER, P. (1975).

Psycholinguistic correlates of academic achievement. Journal of School Psychology, 13, 248-253.

HARE, B., HAMMILL, D., \& BARTEL, N. (1973). Construct validity of selected subtests of the ITPA.

Exceptional Child, 40, 13-21.

HIROSHEN, A. (1969). A comparison of the predictive validity of the revised Stanford-Binet Intelligence Scale and the IIlinois Test of Psycholinguistic Abilities. Exceptional Children, 35, 517-521.

HUIZINGA, R. (1971). The relationship of the IlIinois Test of Psycholinguistic Abilities to the stanford Binet Form L-M and the Weschler Intelligence Scale for Children. Journal of Learning Disabilities, 76 , $451-456$.

HUMPHREY, J., RICE, A. (1973). An evaluation of several methods of predicting full-scale IQ from the ITPA. Journal of Special Education, 7, 133-140.

KIRK, S., \& ELKINS, J. (1974). Summaries of research on the Revised Illinois Test of Psycholinguistic Abilities: final report (pp. 1-106) Arizona University, Tuscon: Department of Special Education.

KIRK, S., \& KIRK, W. (1978). Uses and abuses of the ITPA. Journal of Speech and Hearing Research, 43, $\overline{58-75}$.

KIRK, S., MCCARTHY, J., \& KIRK, W. (1968). Illinois Test of Psycholinguistic Abilities (Revised Edition). Urbana: University of IIlinois Press.

LARSON, G., \& SUMMERS, P. (1982). Comparison of sampling techniques in the measurement of children's morphological development. Journal of Communication Disorders, $15,251-257$.

LUICK, A., AGRANOWITZ, A., KIRK, S., \& BUSBY, R. (1982). Profiles of children with severe oral language disorders. Journal of Speech and Hearing Disorders, 47 , 88-92.

LUMSDEN, J. (1973). Critique of the Illinois Test of Psycholinguistic Abilities. O. K. BUROS (ED) The Eighth Mental Measurements Yearbook (pp. 578-580). Highland Park, N.J.: Gryphon Press. 
MUELLER, M. (1969). Prediction of achievement of educable mentally retarded children. American Journal of Mental Deficiency, 73, 590-596.

MUMA, J., WEBB, P., \& MUMA, D. (1979). Language training in speech-language pathology and audiology: a survey. American Speech-Language Hearing Association, 21 , 467-473.

NEUMAN, K. (1979). A team approach to a language based beginning reading program. Language, Speech and Hearing Services in Schools, 10, 152-158.

NEWCOMER, P. (1975). The ITPA and academic achievement. Academic Therapy, $10,401-406$.

NEWCOMER, P., \& HAMMILL, D. (1975). ITPA and academic achievement: a survey. Reading Teacher, 28, 731-741.

NEWCOMER, P., \& HAMMILL, D. (1976). Psycholinguistics in the Schools (pp. 44-64). Columbus, Ohio: Charles E. Merrill.

NEWMAN, G. (1972). The ITPA grammatic closure subtest: a validity study. University of Texas, Austin: unpublished masters thesis.

PERKINS, W. (1971). Speech Pathology (pp. 346-349). St. Louis: C.v. Mosby.

REESE, L. (1976). A study to determine the construct validity of the grammatic closure subtest as a measure of language ability using signal detection theory. DAI 37:5711A, Stillwater, Oklahoma: Oklahoma State University.

SEDLACK, R., \& WEENER, P. (1973). Review of research on the Illinois Test of Psycholinguistic Abilities. In L. MANN and D. SABATINE (EDS) The First Review of Special Education (pp. 113-163). Philadelphia: JSE Press.

SOMMERS, R. \& \& HATTON, M. (1985). In VanHATTUM, R. (ED) Organization of Speech-Language Services in Schools (pp. 133-156).

STARK, J. (1975). Reading failure: a language-based problem. American Speech-Language Hearing Association, 17, 832-834. 
TIEGS, E., \& CLARK, W. (1970). California Achievement Test (CAT). San Diego: MCGraw Hill.

WAKEFIELD, J., \& CARLSON (1975). Canonical analys is of the WISC and the ITPA. Psychology in the Schools, 12, $\overline{18-20}$.

WASHINGTON, E., \& TESKA, J. (1970). Correlations between the Wide Range Achievement Test, the California Achievement Test, the Stanford-Binet, and the Illinois Test of Psycholinguistic $A b i l i t i e s$. Psychological Reports, 26, 291-294.

WIEDERHOLT, J. (1978). In O.K. BUROS (ED) The Eighth Mental Measurement Yearbook (pp. 431-432). New Jersey: Gryphon Press.

WIIG, E., \& SEMEL, E. (1970). Language Disabilities in Children and Adolescents (pp. 7-12). Columbus, Ohio: Charles E. Merrill. 
APPENDIX A

PERMISSION FORM

I agree to let my child

participate as a subject in the study entitled "Grammatic closure subtest of the ITPA as a Screening Device". This study is carried out by Cathy Newquist, graduate student, under the supervision of Joan McMahon, thesis director, Speech and Hearing Sciences, Portland State University.

The purpose of the study is to compare the scores obtained from a language screening test and the California Achievement Test in order to determine if the Grammatic Closure subtest is useful in identifying children who perform similarly on language and academic tasks.

There are no risks or dangers inherent in the procedures of this study. My child will be given a hearing test and a sentence completion test. In addition, scores from the California Achievement Test will be released to Cathy Newquist. All information will be kept confidential and no names will be mentioned in the study. Subjects are free to withdraw from the study at any time.

Signature of Parent/Guardian

\section{Date}

Birthdate of child

$$
\overline{\text { Mo }}^{-} \frac{}{\text { Day }}-\frac{}{\mathrm{Yr}} \text {. }
$$


APPENDIX B

GRAMMATIC CLOSURE

STIMULUS ITEMS

Demonstration. HERE IS A BED. HERE ARE TWO

1. HERE IS A DOG. HERE ARE TWO

2. THIS CAT IS UNDER THE CHAIR. WHERE IS THIS CAT? SHE IS

3. EACH CHILD HAS A BALL. THIS IS HERS; AND THIS IS

4. THIS DOG LIKES TO BARK. HERE HE IS

5. HERE IS A DRESS. HERE ARE TWO

6. THE BOY IS OPENING THE GATE. HERE THE GATE HAS BEEN

7. THERE IS MILK IN THIS GLASS. IT IS A GLASS

8. THIS BICYCLE BELONGS TO JOHN. WHOSE BICYCLE IS IT? IT IS

9. THIS BOY IS WRITING SOMETHING. THIS IS WHAT HE

10. THIS IS THE MAN'S HOME, AND THIS IS WHERE HE WORKS. HERE HE IS GOING TO WORK, AND HERE HE IS GOING

11. HERE IT IS NIGHT, AND HERE IT IS MORNING. HE GOES TO WORK FIRST THING IN THE MORNING, AND HE GOES HOME FIRST TH ING

12. THIS MAN IS PAINTING. HE IS A

13. THE BOY IS GOING TO EAT ALL THE COOKIES. NOW ALL THE COOKIES HAVE BEEN

14. HE WANTED ANOTHER COOKIE; BUT THERE WEREN'T

15. THIS HORSE IS NOT BIG. THIS HORSE IS BIG. THIS HORSE IS EVEN

16. AND THIS HORSE IS THE VERY

17. HERE IS A MAN. HERE ARE TWO 
APPENDIX B (CONT'D)

18. THE MAN IS PLANTING A TREE. HERE THE TREE HAS BEEN -

19. THIS IS SOAP AND THESE ARE

20. THIS CHILD HAS LOTS OF BLOCKS. THIS CHILD HAS EVEN

21. AND THIS CHILD HAS THE

22. HERE IS A FOOT. HERE ARE TWO

23. HERE IS A SHEEP. HERE ARE LOTS OF

24. THIS COOKIE NOT VERY GOOD. THIS COOKIE IS GOOD. THIS COOKIE IS EVEN

25. AND THIS COOKIE IS THE VERY

26. THIS MAN IS HANGING THE PICTURE. HERE THE PICTURE HAS BEEN

27. THE THIEF IS STEALING THE JEWELS. THESE ARE THE JEWELS THAT HE

28. HERE IS A WOMAN. HERE ARE TWO

29. THE BOY HAD TWO BANANAS. HE GAVE ONE AWAY; AND HE KEPT ONE FOR

30. HERE IS A LEAF. HERE ARE TWO

31. HERE IS A CHILD. HERE ARE THREE

32. HERE IS A MOUSE. HERE ARE TWO

33. THESE CHILDREN ALL FELL DOWN. HE HURT HIMSELF; AND SHE HURT HERSELF. THEY ALL HURT 
APPENDIX C

RAW DATA: FIRST AND SECOND GRADE SUBJECTS' BIRTHDATES, CHRONOLOGICAL AGE IN MONTHS, GRAMMATIC CLOSURE SCALED SCORES, CAT GRADE LEVEL EQUIVALENT

\section{First Grade}

\begin{tabular}{|c|c|c|c|c|}
\hline $\begin{array}{l}\text { Subject } \\
\text { Number }\end{array}$ & Birthdate & $\begin{array}{l}\text { C.A. } \\
\text { (mos) }\end{array}$ & $\begin{array}{c}\text { Scaled } \\
\text { G.C. Scores } \\
\end{array}$ & $\begin{array}{c}\text { CAT Grade } \\
\text { Level Scores }\end{array}$ \\
\hline 1 & $2-12-76$ & 74 & 41 & 1.5 \\
\hline 2 & $10-29-75$ & 78 & 42 & 1.6 \\
\hline 3 & $10-23-75$ & 78 & 58 & 2.9 \\
\hline 4 & $10-4-75$ & 78 & 40 & 1.9 \\
\hline 5 & $9-22-75$ & 79 & 43 & 1.7 \\
\hline 6 & $9-21-75$ & 79 & 40 & 1.7 \\
\hline 7) Twins & $9-1-75$ & 79 & 45 & 2.5 \\
\hline 8) & $9-1-75$ & 79 & 42 & 2.2 \\
\hline 9 & $8-30-75$ & 80 & 41 & 2.0 \\
\hline 10 & $8-24-75$ & 80 & 32 & 2.2 \\
\hline 11 & $7-18-75$ & 81 & 44 & 2.4 \\
\hline 12 & $7-9-75$ & 81 & 40 & 2.0 \\
\hline 13 & $7-2-75$ & 81 & 26 & 1.9 \\
\hline 14 & $6-27-75$ & 82 & 43 & 1.8 \\
\hline 15 & $6-18-75$ & 82 & 36 & 1.8 \\
\hline 16 & $6-19-75$ & 82 & 38 & 2.3 \\
\hline 17 & $4-16-75$ & 84 & 32 & 2.1 \\
\hline 18 & $4-7-75$ & 84 & 36 & 1.7 \\
\hline 19 & $3-30-75$ & 85 & 47 & 1.6 \\
\hline 20 & $3-30-75$ & 85 & 51 & 2.1 \\
\hline 21 & $2-28-75$ & 86 & 41 & 1.8 \\
\hline 22 & $2-3-75$ & 86 & 41 & 2.0 \\
\hline 23) Twins & $2-1-75$ & 86 & 36 & 1.7 \\
\hline 24) & $2-1-75$ & 86 & 45 & 1.7 \\
\hline 25 & $1-30-75$ & 87 & 36 & 2.3 \\
\hline 26 & $1-23-75$ & 87 & 33 & 2.0 \\
\hline 27 & $12-21-74$ & 88 & 27 & 2.3 \\
\hline 28 & $12-16-74$ & 88 & 51 & 2.3 \\
\hline 29 & $12-13-74$ & 88 & 37 & 1.9 \\
\hline 30 & $12-3-74$ & 88 & 28 & 1.8 \\
\hline 31 & $11-22-74$ & 89 & 45 & 3.4 \\
\hline 32 & $11-20-74$ & 89 & 30 & 2.2 \\
\hline 33 & $11-3-74$ & 89 & 30 & 1.9 \\
\hline 34 & $10-22-74$ & 90 & 30 & 2.0 \\
\hline 35 & $10-14-74$ & 90 & 39 & 2.9 \\
\hline 36 & $10-5-74$ & 90 & 37 & 2.1 \\
\hline
\end{tabular}




\section{APPENDIX C (CONT'D)}

\section{Second Grade}

\begin{tabular}{|c|c|c|c|c|}
\hline $\begin{array}{l}\text { Subject } \\
\text { Number }\end{array}$ & Birthdate & $\begin{array}{l}\text { C.A. } \\
\text { (mos) }\end{array}$ & $\begin{array}{c}\text { Scaled } \\
\text { G.C. Scores }\end{array}$ & $\begin{array}{r}\text { CAT Grade } \\
\text { Level Scores }\end{array}$ \\
\hline 37 & $10-2-74$ & 90 & 34 & 2.4 \\
\hline 38 & $9-23-74$ & 91 & 39 & 2.7 \\
\hline 39 & $8-28-74$ & 92 & 39 & 2.4 \\
\hline 40 & $8-12-74$ & 92 & 40 & 3.3 \\
\hline 41 & $8-4-74$ & 92 & 35 & 3.2 \\
\hline 42 & $8-1-74$ & 92 & 37 & 2.3 \\
\hline 43 & $7-25-74$ & 93 & 37 & 3.3 \\
\hline 44 & $7-24-74$ & 93 & 41 & 2.0 \\
\hline 45 & $7-19-74$ & 93 & 31 & 2.0 \\
\hline 46 & $7-17-74$ & 93 & 38 & 2.7 \\
\hline 47 & $7-9-74$ & 93 & 37 & 2.7 \\
\hline 48 & $7-1-74$ & 93 & 31 & 2.0 \\
\hline 49 & $6-15-74$ & 94 & 44 & 3.6 \\
\hline 50 & $6-8-74$ & 94 & 41 & 3.7 \\
\hline 51 & $6-3-74$ & 94 & 38 & 1.9 \\
\hline 52 & $5-19-74$ & 95 & 31 & 3.3 \\
\hline 53 & $5-16-74$ & 95 & 43 & 2.7 \\
\hline 54 & $4-9-74$ & 96 & 37 & 2.1 \\
\hline 55 & $4-20-74$ & 96 & 46 & 3.6 \\
\hline 56 & $4-19-74$ & 96 & 42 & 3.6 \\
\hline 57 & $4-9-74$ & 96 & 38 & 2.7 \\
\hline 58 & $3-30-74$ & 96 & 36 & 2.6 \\
\hline
\end{tabular}


APPENDIX D

ERROR APPEARANCE, PROGRESSION AND

DISAPPEARANCE PATTERN

1. dog -- dogs

2. over -- on

3. him - his

4. bark -- barking

5. dress -- dresses

6. open -- opened

7. milk -- of milk

8. John -- John's

9. write -- writes -- was writing -- writed -- wrote

10. no errors

11. night -- in the night -- at night

12. work(er/man) -- paint(ing) man -- painter

13. done -- gone -- ate -- aten -- eaten

14. no more (candy) -- none -- any

15. big -- bigger

16. big -- bigger -- biggest

17. mans -- man -- mens -- men

18. growed -- growned -- grown

19. Soaps -- soap

20. lot -- lotter (mortherer) -- more

21. more --even more (mortherest) -- morest -- most

22. foots -- foot -- feets -- feet

23. sheeps -- sheep

24. good -- very/more good -- gooder -- better

25. gooder -- goodest -- best

26. On the wall -- hanged/hangeded -- hang -- hung

27. steals -- stealed/stoleded -- stoled, stole

28. womans -- woman -- womens -- women

29. him -- hisself -- himself

30. leaf -- leafs -- leaves

31. childs -- child -- children

32. mouses -- mouse -- mice

33. theirself -- theirselfs -- themself -- themselves 